\title{
Enhancing the communication potential of smart metering for energy and water
}

- Article DOI https://doi.org/10.1016/i.jup.2018.11.002

- Reference: Aleksandra Michalec, Enda Hayes, James Longhurst, David Tudgey, Enhancing the communication potential of smart metering for energy and water, Utilities Policy, Volume 56, 2019, Pages 33-40, ISSN 0957-1787,

- Journal: Utilities Policy

\begin{abstract}
The success of water and energy smart metering is highly contingent on a successful communication strategy. We report on the findings from a qualitative study involving discourse analysis of customer messaging and focus groups with utility professionals. Discourse analysis suggests that the main framings applied are "control", "convenience", and "savings". Focus groups revealed paradoxes contained in these framings as the participants associate metering with the loss of control over private data, inconvenience during installation process and lack of financial gains if customers' lifestyles cannot support "smart" decisions. Future communications ought to be tailored to the consumers' values and needs.
\end{abstract}

\section{Keywords:}

smart meters, co-production, climate justice,

\section{Highlights:}

*Promotional materials do not reflect the full functionality of metering

*Tariff re-design and transparent communication needed for fair implementation

*Potential for collaboration and mutual learning between water and energy sectors

\section{Funding:}

The project is jointly funded by the University of the West of England, Bristol City Council and Lloyd's Register Foundation, a charitable foundation helping to protect life and property by supporting engineering-related education, public engagement and application of research.

Conflict of interest: None. Bristol City Council's sustainability team is the funder and stakeholder in the research. However, the role of the council is limited to the provision of official local government datasets, the funders were not involved in participants' selection, research design, data collection or analysis.

\section{Abbreviations:}

ABC- Attitude, Behaviour, Choice

BCC - Bristol City Council

DA - Discourse Analysis

DSM- demand-side management

EU - European Union

IHD - In-home Display

LSOA - Lower Super Output Area

\section{Introduction}

Meters are devices recording resource consumption at a fine unit of analysis. In their simplest form, they enable issuing accurate electricity, gas or water billing as opposed to the approximated statements (DBEIS, 2017b). Their functionality is predicted to increase with the advance of smart homes and smart grid abilities, however, the current available technology is at various stages of development and uptake, depending on the location and sector. The 
devices could provide basic information on the resources consumption or go one step further and facilitate efficient behaviours. Sovacool et al. (2017) listed 67 anticipated benefits of energy metering. They included some advanced functionalities, such as: uptake of microgeneration, easy switching between suppliers, new opportunities for energy storage.

Despite the industry promises of improved carbon and water management, the research on metering as a demand-side management (DSM) tool provides conflicting evidence with regards to its effectiveness. Metering can only have a positive impact on resource efficiency provided that it: a) improves the management of the energy grid and tackles water leaks (Cheong et al., 2015); b) leads to changes at the household level (e.g. decrease in consumption, purchase of smart equipment, change in social norms) (Bradley et al., 2014; Buchanan et al., 2014). The extensive literature on climate change communication suggests that the appropriate engagement strategy is vital for the effective adoption of new technologies (ibid.)

Therefore, the primary aim of the paper is to understand the shortcomings of current smart meter communications by answering the following questions:

1. How is metering understood across the water and energy practitioners in Bristol, UK? 2. What is the role of "sustainability", "fairness", and "smartness" in the discourse formation? 3. How to improve communication materials?

\section{Theory}

\subsection{User perceptions of metering}

The research is not yet clear on whether metering is an effective tool of DSM - the answers range from optimistic (Beckel et al., 2014), cautious (Spence et al., 2015; Bradley et al., 2014, McKenna, 2012) to sceptical (Loftus, 2006). Metering deployment could potentially facilitate targeted resource efficiency programmes (Beckel et al. 2014) and become an essential step towards the developments of smart tariffs, which could respond to the availability of the grid and engage with the existing social practices (Torriti, 2017).

However, the successful rollout of metering is highly contingent on the interactions between the users and the technology: the perceptions, communications, design and understanding. Spence et al. (2015) point out current shortcomings in public engagement of DSM. Similarly, Buchanan et al., (2014) call for a redesign of the current smart meters interfaces, In-Home Displays (IHD) and McKenna et al. (2012) outline the unresolved privacy issues around the data. Sovacool et al. (2017) concluded that social issues like apathy and resistance cannot be overlooked while dealing with the technical "teething" problems.

Since public engagement materials are often the first point of information between the user and the technology, they have a significant potential to influence perceptions and acceptability. Previous research exploring customers' perceptions provides initial recommendations on future engagement with the "smart" technologies. A survey of over 2400 British householders concluded that those concerned about the cost are the least likely to accept DSM and share their data, whereas participants concerned about climate change were more likely to be supportive of DSM (Spence et al., 2015). Seyranian et al. (2015) researched the effectiveness of public engagement in the water context. They conducted an intervention study of over 370 American households, who received a variety of public engagement materials. The researchers found that the individuals were most likely to reduce their water consumption if they received messages related to the social norms and personal values. On the other hand, the knowledge-deficit approach (i.e. only providing factual information) proved to be the least effective one (ibid.).More recently, Montginoul and Vestier (2018) conducted a natural field experiment on 261 French households, testing how communication methods affect smart 
water metering uptake. Their study resulted in an overall low adoption rate, which was linked to the lack of incentives, such as "smart" tariffs.

\subsection{Metering as a science-policy issue}

Existing experimental studies on metering provide valuable insights into customers Attitudes, Behaviours and Choices (ABC), however, the $A B C$ approach alone does not answer the political and ethical questions related to DSM technologies (Shove, 2010). For example, deployment of metering is closely related to the tariff redesign, which is a contentious issue both in water and energy industries.

French energy consumers who discussed the time of use ${ }^{1}$ tariffs voiced criticisms arguing that time of use tariff leaves behind those, who do not have the flexibility to shift their energy use beyond peak times (Bertoldo et al. 2015). The analysis of the Australian block tariffs ${ }^{2}$ concluded that such water pricing was neither efficient nor fair, (Sibly and Tooth, 2014). Loftus (2006) went even further arguing that the act of water meter installation alone contributes to the commodification of water, which ought to remain a basic human right. Although an emerging scholarship describes models for optimal pricing options (Eid et al., 2016; Fahradi and Taheri, 2017), there are only weak signs of a wider tariff debate among the public (Hielscher and Sovacool, 2018).

Another political issue related to metering is the question of governance. Smart meters are not solely installed to reduce customers' bills. In fact, many of their predicted benefits relate to the company savings' and network improvements, such as reduced operational costs, enhanced data management or avoided peak demand (Sovacool et al., 2017). Rodney et al. (2018) vision the future of the possible multi-utility service providers synthesising big data on water and energy use. Helmbrecht et al. (2017) argue that smart metering is vital if water and energy resources were to be managed in integration.

\subsection{Theoretical framework}

Since fairness and governance of smart transitions are subjects of academic and policy debates, the would benefit from appropriate theoretical lenses. Sovacool et al. (2016) suggest reframing climate change policies as justice concerns by drawing attention to availability, affordability, transparency, equity and responsibility of policy decisions. In order to make this framework operational, the concept of climate justice must be directly addressed at the policymakers, designers, utilities practitioners and the users themselves.

Furthermore, an increasing interest in the integrated resources management led to the development of the Water-Energy Nexus concept, which draws attention to synergies, tradeoffs, efficiencies and potential for collaboration (Hoff, 2012; Rodney et al., 2018; Helmbrecht et al., 2017). The Nexus agenda is not yet crystallised within the context of UK environmental management, however its proponents argue that the improved data on water and energy will lead to integration in policymaking and improved sustainability and security of resources (Cairns and Krzywoszynska, 2016). In the wake of the urgent challenges such as droughts, thirsty energy sources (e.g. fracking or nuclear energy), population growth; both Nexus and climate justice framings could offer novel insights.

\footnotetext{
${ }^{1}$ Time of use tariff has different time periods with varying price blocks (e.g. called 'peak' weekday evenings or 'off-peak' weekend daytime). (CAB, 2017)

${ }^{2}$ Block tariff establishes zero-tariff for consumption up to a certain threshold. The zero-tariff, which equates the household "essential needs", charges below the real production cost as an incentive for clients to reduce their consumption. Following the zero-tariff block, each successive block is priced higher. The aim of the tariff is to encourage low consumption while reducing the pressure on low-income households (Sibly and Tooth, 2014)
} 
Nevertheless, the literature on the practical understanding of climate justice and Water-Energy Nexus in the context of metering is limited. This paper aims to bridge this gap by exploring the practitioners' understanding of the concepts like "fairness", "sustainability", "smartness" or "the nexus" when applied to the smart metering debate.

\subsection{Policy context}

Smart metering of the energy sector is a part of the European Commission's recommendation on energy efficiency 2012/148/EU (European Commission, 2012), subsequently rolled out by the UK national government (DBEIS 2017b). In the UK, Smart Meters GB is the national campaign encouraging installation of smart energy meters (Smart Energy GB, 2017).

Locally, multiple metering pilot projects were funded in the deprived areas of Bristol, which suggests that metering could help to tackle fuel or water poverty by encouraging sustainable behaviours (Connecting Bristol, 2016; KWMC, 2013). However, the potential for an overall decrease in resource consumption might be limited if the building efficiency is sub-optimal (e.g. single glazed windows, drafts, leaking taps). Offering behavioural change as a way to tackle fuel poverty comes with an assumption that people in deprived areas waste energy, therefore metering could induce behavioural change (Shove, 2010). The local data on energy use suggests otherwise - people in 10 most deprived areas consume far less gas compared to their more affluent counterparts (Table 1).

\begin{tabular}{|c|c|}
\hline \multicolumn{2}{|c|}{ Mean gas consumption } \\
\hline $\begin{array}{l}\text { Average from 10 most deprived } \\
\text { LSOAs (kWh/meter) }\end{array}$ & $\begin{array}{l}\text { Average from 10 least deprived } \\
\text { LSOAs (kWh/meter) }\end{array}$ \\
\hline 9176.4 & 17245.1 \\
\hline
\end{tabular}

Table 1. Average mean gas consumption in 10 most and least deprived LSOAs in Bristol in 2015 (raw gas consumption data from DBEIS, 2015a; deprivation data from BCC, 2015)

In contrast, measuring water consumption and upgrading the "grid" from analogue to smart metering is not a current policy priority in the UK (Priestley, 2016). In fact, it is estimated that a half of the UK population does not have a water meter, in which case their water bill is decided by the so-called "rateable value" of the property - an estimation of a rental value of a property in 1990 (Bennett, 2013). Compulsory universal water metering has so far only been introduced in parts of the UK subjected to the highest water stress (i.e. south-east England). However, many English water companies see metering as a useful tool for resource management and are compelled to promote it to their customers (Priestley, 2016).

Similarly, the water dimension is mostly absent from smart and green policies at the urban scale. This might be due to the fact that water efficient behaviours and infrastructure are largely outside of the remit of the local authorities. In the UK, the water sector is privatised and regionally monopolised, which hinders access to data, knowledge transfer and cross-sectoral governance (Loftus et al., 2016).

\section{Methods}

\subsection{Methodology framework}

The researchers adopted a knowledge co-production approach, combining two qualitative methods: discourse analysis of metering promotional materials and two focus groups with metering experts. Co-production emphasises the deeper involvement of non-academic actors in the research process (Jasanoff, 2010). In this case, participants selected the focused research question ("communication strategy") after being presented with the wider theme 
("water and energy meters"). The paper authors conducted the first iteration of data analysis and presented the results for further discussion during the participants' meetings and a free public event organised by the Bristol Energy Network ${ }^{3}$ in July 2018.

Co-producing research with public, private and charity sectors is useful for capturing different discursive framings, cross-sectoral learning and creating future opportunities for collaboration. Furthermore, it facilitates an active deliberation on policy recommendations (Howarth and Monasterolo, 2016). Conducting qualitative and participatory research together with both water and energy metering experts complements currently prevailing quantitative and natural sciences approaches to the Water-Energy Nexus issues (Albrecht et al., 2018).

The research was held between June 2017 and July 2018 and it involved the following stages:

- Literature review of the smart metering scholarship and policy context (Section 2);

- Discourse analysis (DA) of metering promotional materials from four organisations (Section 4.1);

- Thematic analysis of two focus groups (Sections 4.2-4.6.);

\subsection{Discourse analysis of promotional materials}

The notion of the discourse describes the sum of communications on a particular topic: the language, form, images, metaphors and arguments used. Discourses, especially if written by authorities (in this case policymakers, experts or utility providers), indicate what can and cannot be expressed or challenged by the audience - which information is seen as a "fact" and which is open to a dispute (Bax, 2011). DA critically unpacks the current debates in the areas of water and energy metering in order to evaluate whether and how sustainability, smartness and climate justice ambitions are embedded in the promotional materials. Documents selected for the analysis were websites and online leaflets providing information and promoting metering in the water and energy sectors. The researchers selected four sources from two key local service providers and two national-level organisations overseeing metering deployment. The researchers thoroughly analysed each document to unpack the rhetorical and linguistic tools used. For example, they looked to determine the overall tone of the message (e.g. promotional, informational), arguments fore- and backgrounded (e.g. placed in the title vs at the bottom of the page), and the main frames applied (e.g. savings, sustainability, control). Table 2 lists the documents analysed together with the heuristic for the process (adapted from Bax, 2011).

\begin{tabular}{|c|c|c|}
\hline Documents analysed & $\begin{array}{c}\text { Description of } \\
\text { organisation }\end{array}$ & Heuristic \\
\hline $\begin{array}{l}\text { Ofwat (2013) } \\
\text { Water meters- your questions answered } \\
\text { https://www.ofwat.gov.uk/wp- } \\
\text { content/uploads/2015/11/prs lft } 101117 \text { meters.pdf }\end{array}$ & $\begin{array}{l}\text { National water } \\
\text { industry regulator }\end{array}$ & \multirow{3}{*}{$\begin{array}{l}\text { - Location in the text } \\
\text { (e.g. title/ front } \\
\text { page/ last page) } \\
\text { - Aim (e.g. inform/ } \\
\text { promote) } \\
\text { - Main framings used } \\
\text { (e.g. savings, } \\
\text { convenience, } \\
\text { control) } \\
\text { Unchallenged } \\
\text { assumptions? }\end{array}$} \\
\hline $\begin{array}{l}\text { Bristol Water (2016) } \\
\text { Water meters explained } \\
\text { https://www.bristolwater.co.uk/your-home/water- } \\
\text { meters/ }\end{array}$ & $\begin{array}{l}\text { Local water } \\
\text { services provider }\end{array}$ & \\
\hline $\begin{array}{l}\text { Bristol Energy (2016) } \\
\text { Your smart meter and in-home display guide } \\
\text { https://www.bristol- } \\
\text { energy.co.uk/sites/default/files/Smart-Metering- } \\
\text { Guide-WEB-low.pdf }\end{array}$ & $\begin{array}{l}\text { Municipally owned } \\
\text { local energy } \\
\text { company }\end{array}$ & \\
\hline
\end{tabular}

\footnotetext{
${ }^{3}$ Bristol Energy Network is an umbrella organisation for individuals and community groups with an interest in energy in Bristol and the surrounding area.
} 
Smart Energy GB (2017)

Smart meters- the simple way to control your energy use

https://www.smartenergygb.org/en
National campaign

for the smart

meter rollout
- Admitted

uncertainties?

- Provided balanced arguments?

Table 2. List of documents analysed and a heuristic for DA.

\subsection{Focus groups}

If DA intended to understand how utility providers construct their engagement, focus groups aimed to clarify metering professionals regard metering as a "sustainable", "fair" and "smart" tool of DSM. In doing so, the discussions explored the understanding of the purpose and potential of metering across the utilities professionals in Bristol, UK. Environmental policies do not arise in a conceptual vacuum, they are a result of debates between stakeholders across the sectors, who build trust and rapport while deliberating on their language and goals (Harris and Lyon, 2013).

Following the exploratory part of the event, participants discussed the recommendations for the policy and public engagement. Focus group was deemed an appropriate method for this research, as it taps into the interactions between participants, observing the process of discourse formation, agreements and disagreements (Morgan, 1998). This is particularly relevant for the policy issues, which are commonly co-produced in collaboration between private, public and charity sectors (Howarth and Monasterolo, 2016; Harris and Lyon, 2013).

The following paragraphs outline the research design. First, the researchers identified key local organisations with experience in water and energy metering. Then, they approached eligible organisations and purposively selected participants, so that the group composition achieves the diversity of sectors and roles. As a result, the researchers conducted two focus groups, with 6 participants in each (Table 3 ).

\begin{tabular}{|c|c|c|c|}
\hline \multicolumn{2}{|c|}{ Focus group 1} & \multicolumn{2}{|c|}{ Focus group 2} \\
\hline Participant & Sectors & Participant & Sectors \\
\hline FG1_P01 & Energy researcher & FG2_P01 & Water company \\
\hline FG1_P02 & $\begin{array}{l}\text { Civil Servant } \\
\text { (Smart Futures) }\end{array}$ & FG2_P02 & Energy company \\
\hline FG1_P03 & Energy Company & FG2_P03 & $\begin{array}{l}\text { Community Energy } \\
\text { (Local Project) }\end{array}$ \\
\hline FG1_P04 & Water Company & FG2_P04 & $\begin{array}{l}\text { Community Energy } \\
\text { (Network) }\end{array}$ \\
\hline FG1_P05 & Water Researcher & FG2_P05 & $\begin{array}{l}\text { Civil Servant } \\
\text { (Household } \\
\text { Resource } \\
\text { Efficiency) }\end{array}$ \\
\hline FG1_P06 & $\begin{array}{ll}\text { Community } & \text { Energy } \\
\text { (Network) } & \end{array}$ & FG2_P06 & Water researcher \\
\hline
\end{tabular}

Table 3. Focus groups participants

The discussions lasted 1.5 hours each, which included both pre-scripted questions and the critique of existing metering promotional materials (i.e. documents specified in Table 2). The researcher-facilitator focused the discussion on the purpose of metering, biggest challenges, cross-sectoral learning and recommendations for communication. In order to establish a sense of shared language, the researcher-facilitator asked the participants to discuss the terms commonly used in their roles, such as "sustainability" or "fairness", "smartness". 
The focus group data were audio recorded, transcribed and examined using thematic analysis. The method allows capturing patterns and grouping complex qualitative data (Braun and Clarke, 2006). First, the data were analysed at the descriptive level, establishing codes derived from the questions (e.g. "solutions", "challenges", "purpose of metering"). Then, after an indepth reading, the interpretive and analytical inductive codes were captured to compose a thematic narrative present in section 4.

\section{Results and discussion}

\subsection{Discourse analysis of marketing materials}

The researchers analysed four customer-oriented documents on metering from the following organisations: Bristol Water, Ofwat, Bristol Energy, Smart Energy GB. The themes prevailing in the metering promotional materials are "control", "savings" and "convenience", as these are the keywords appearing most commonly in each document, often on the first page or written in a bigger font. The messages emphasize that the customers will be able to gain control over spending" Bristol Energy, 2016) and therefore lower their bills as a result of meter installation ("You could save up to $£ 100$ on your water bill"; Bristol Water, 2016). The leaflets also emphasize the ease of installation process and the convenience benefits resulting from having a meter ("No more having to read the meter or trying to work out your bill. No more strangers coming into your home for meter readings"; Smart Energy GB, 2017). However, despite the commonalities, there are significant differences in communication, depending on the sector and organisation.

Smart Energy GB repeatedly uses the discourses of control, savings, and convenience notably, these are all benefits to the individual. Even the title of the leaflet - "The simple way to control your energy use" - is meant to evoke the above qualities. When justifying the rollout in the further paragraphs, the organisation provides the context of the EU-led regulation implemented in the interest of mitigating climate change and upgrading the energy grid. It is worth noting that the reasons for policy implementation are not located on the landing page or the front of the leaflet, suggesting that the benefits to the environment and the energy sector are backgrounded from the promotional strategy.

Similarly, Bristol Energy uses the discourses of "control" and "savings". In addition, they emphasize the environmental and fairness values from the beginning, providing a more collectivist justification of metering. Their messaging is characterised by a level of transparency and honesty - owning a meter will not make a difference, engaging with it could do so.

"It's important to note that just by having a smart meter and in-home display, you're not automatically going to use less energy and start spending less money, but these devices put the power in your hands. Using in-home display will give you a greater understanding of what you're spending, identifying when you use the most energy and highlighting in near real-time they way you use energy in your home". (Bristol Energy, 2016)

Bristol Water focuses their messaging on savings and the ease of application and installation process, both benefits to the individual. Additionally, one of the benefits of metering outlined on the landing page is "it helps us to detect leaks much quicker" (Bristol Water, 2016), an advantage to the industry. However, this point is not elaborated further in the document. The Bristol Water leaflet contains presumption about customers' attitude to water ("Most of us do everything we can to save water, we know it's important to everyday life" Bristol Water, 2016). Further pages of the document explain how the metered water bill might change, revealing 
that it is, in fact, a function of a number of householders, number of the rooms, personal water usage and the presence of the garden. The final page of the leaflet contains an application form asking questions like "Is there an externally located stop tap controlling water to the property? Do you share water supply with your neighbour?" (Bristol Water, 2016). There is no evidence whether the above questions are easily answerable by an average water customer, indicating that the application process might not in practice be perceived as "easy".

The communication prepared by the industry regulator, Ofwat, has an entirely different character as it is informative and explanatory rather than promotional. Ofwat justifies metering as an environmental and strategic intervention, aiming to improve the management of scarce water supplies and increasing demand as a result of population growth. The document aims to improve the bill literacy, providing a comparison of water tariffs in the unmetered vs metered scenarios. It then reports that "some people regard meters as the fairest way to charge for water and sewerage services. This is because you pay for how much water you use" (Ofwat, 2013). However, Ofwat does not comment on this opinion nor elaborates why other water tariffs would not be as fair.

The main difference between the leaflets is the inclusion of individualist versus collectivist arguments. The second difference is between informational versus promotional character of the marketing materials. Notably, the individualist arguments were commonly presented in the promotional materials, whereas collective reasoning was included in the informational materials. However, it should be noted that on a few occasions, the messages managed to be both promotional and informational as well as contain both individualist and collective arguments, e.g.:
"Smart meters are part of the government's plan to bring our energy system up to date. By 2020, every home in Great Britain will be able to use smart meter technology to see exactly how much energy they're using, and what it's costing in pounds and pence. In addition to these immediate benefits, the rollout also lays the foundation for Great Britain's move to a lower carbon economy and a secure energy supply" (Smart Energy GB, 2017)

Combining a range of arguments and communication styles results in the honest and transparent disclosure about the limits and the potential benefits of metering.

\title{
4.2. Theme 1: Misplaced aims
}

DA of promotional materials revealed that meters are commonly promoted under the discourses of convenience and control. Yet, five focus groups participants reported that the customers frequently perceive the installation process as an inconvenience, which is seen as a major barrier to the uptake. Not only participants referred to what they imagine "lay" customers think (recorded 12 times). In fact, focus group members, all with professional expertise in metering, recalled their own experiences as energy customers (recorded 6 times):

\begin{abstract}
"My energy company contacted me, and their letter was "we need to turn every appliance off in your house" - but I don't want to. I had an argument with that woman for 15 minutes, because I just don't want one...as a consumer I have that choice" (Water Company)
\end{abstract}

Similarly, the discourse of control over energy and water use stands in contradiction with the perceived loss of control over privacy and data (recorded 16 times): "With water 2/3 of water consumption is done in privacy and in a bathroom and maybe you don't want people to know what your bathroom habits are" (Water academic). On the other hand, ensuring adequate privacy settings could pave the way for the innovative ways of engagement, such as data visualisation or competitions with incentives. 


\begin{abstract}
"If you want people to engage and to know what their data mean, then having them compete with other members of their family or the friendship group takes that ownership away from the organisational structure, but it does actually create a real engagement that may last a lot longer than anything that comes top-down" (Water Company)
\end{abstract}

Water and energy sectors would have to consider at what level the data are gathered (e.g. person, household, LSOA, city) and whom they are shared with (e.g. utility company, the government, academics, advertisers). In its current state, the privacy settings hinder accessing, analysing and visualising data which could be useful for effective public engagement. If water and energy sectors are serious about working on the nexus issues, they ought to consider the trade-offs between data privacy and data accuracy.

Community Energy 1: If there was a target for Bristol average per capita consumption for water then you see where you are comparing to the average.

Water Company: We do this.

Community Energy 1: Oh, you do?

Community Energy 2: Do you include that information on your customer sheet?

Water Company: We don't do it at the moment, largely because we don't know how many people are in the house.

Participants admitted that the promotional strategies are yet to address the above issues, and the issue of right communication deserves further research. Since the customers have not received convincing arguments, they do not have the reason give up their data privacy:

\begin{abstract}
Energy company: I think the energy industry as a whole hasn't really made a good enough offer to people...A really good offer, a really good service, as long as they give away a certain amount of their data privacy around their energy consumption. That's the exchange that people can understand, can opt into...
\end{abstract}

\title{
4.3. Theme 2: Intelligent choices
}

The purpose of metering, as explained by the participants, turns out to differ significantly from the justification provided in the promotional materials. Participants agreed that "smartness" is about enabling "intelligent choices" - both for the customers and the industry (recorded 13 times): "I'm just going to get a highlighter pen and put "intelligent choices", I'd highlight that bit, because I think that unless you're using it to inform decision making then it's not smart, then it's just measuring stuff..." (Energy Researcher). In fact, the "convenience" and "savings" arguments have been explicitly categorised as "not smart per se".

Water participants focused on the industry's intelligent choices, "We can spend millions of pounds replacing pipes but if we have no idea where the water is going... the data is far more important to make those informed decisions" (Water Company). In turn, energy participants emphasized the potential to make "smart decisions" on the street or neighbourhood level,

"What you could potentially do on a street level is a demand-side response. So if there are particular times of the day, where there is a particularly high demand on the grid, you could aggregate the energy from a collection of houses and decrease the consumption based on turning on and off appliances. And if you can pull that into a street or a neighbourhood, 
Although the implementation of smart meters is a matter of national legislation, the emerging technologies and users' experiences are often tested at a neighbourhood level. Such pilot projects are usually coordinated by the local actors, such as researchers, local authorities or utility companies. Participants reflected on their recent work in this field, which enabled them to test the potential for "intelligent choices" in metering. Local initiatives recalled during the focus groups were: Replicate, CHEESE, Smart Spaces, Owen Square Community Energy, UWE Student Accommodation Water Strategy. The highlighted lessons learnt from the past projects were:

- The question of the capacity to change lifestyle and purchase smart products in disadvantaged households;

- The need for the re-design of energy tariffs to e.g. block pricing or time-of-use tariff.

Gathering fine level data on energy and water consumption is essential for the introduction of smart tariffs, however, the technology alone does not guarantee that all customers will benefit in an equitable way: "One flipside of 'smart' to be aware of, the potential for that not to be fair... and to actually just privilege people who are more tech-savvy or who have the ability to organise their lifestyle" (Energy Company). Participants are already aware of the potential for injustices once smart energy and water meters are widespread. To counteract this, they focus the current efforts on piloting metering among deprived communities. However, the conundrum remains: even the best design of IHD and most innovative tariffs will not lift people out of fuel and water poverty, if these residents do not have the capability to make changes to their lifestyles, e.g. due to illness, shift work pattern or short term renting contracts.

\subsection{Theme 3: Focus on the needs}

Meters have been originally designed as the technology facilitating energy and water efficiency, and therefore sustainable management of environmental resources. Throughout the discussions, participants emphasised the need to reconcile "sustainability" and "fairness" agenda (synonyms of "fairness" were recorded 57 times). However, there are potential complications as these agenda serve two different types of customers and need two tailored policy approaches accordingly. One of the participants suggested: "One of the ways to look at it, that there are two markets, there's early adopter market and what we call vulnerable households in the industry" (Energy Company).

Metering alone does not tackle fuel and water poverty. Yet, reducing resource consumption among the affluent residents is essential for meeting the climate mitigation targets. Participants brought attention to this paradox and suggested cross-subsidising and explicit differentiation between these two markets while designing policies and public engagement.

"The contradiction is - we actually need the early adopters, we need the people who don't need to worry about the bills, otherwise we won't have the technology available for the lower retail cost in place. Then the early adopters can cross-subsidise a charitable project that will sort out the mess of fuel poverty and water poverty." (Civil Servant)

There are numerous ways to conceptualise the "social" side of meters, with terms like social justice, equality, inclusion, vulnerability, class used interchangeably. The discussion, however, would always eventually refer to defining, measuring and providing for "the basic level of need". e.g.: 
"Just to tie it back to sustainability issues, one the possible benefits is that metering is, you can then say, 'here is the social amount that someone would need for the social use level that we think we would price it to the lower level', so you'd have that block pricing, and then you'd charge extra" (Energy Researcher)

Framing metering as a technology helping to define, measure and provide for the basic level of need led to a discussion about appropriate tariffs and universal water metering. Community Energy, Water Researcher and Water Company participants disagreed on the perceived fairness of block tariffs. Although such pricing structure could include the notion of affordable water to cover the basic level of need, it is not clear how the "basic level of need" would be determined: "My problem with block pricing is... and actually, I have quite a big problem with it... which is that it means that I get to decide what somebody else needs and why the hell should it be up to me?" (Water Company).

Considering the introduction of the universal water metering calls for a debate on the relationship between the people and water. Although water metering is promoted as the "fairest way to pay" (section 4.1), one of the participants pointed out that the current tariff based on rateable value is more affordable: "People who don't have a water meter, pay [bills] on the rateable value of their house, and there is an element of affordability in that, the assumption that if you live in a smaller house, that is of a lower rateable value" (Water Researcher).

Nevertheless, as one of the participants stated, "water is sort of fundamental, you need to drink" (Civil Servant). Access to clean water and sanitation is recognised as a human right by the United Nations (UN, 2010). Re-designing the tariffs using the data obtained from metering provides an opportunity to introduce fair, transparent and data-supported policies, which would recognise water as a "human right" as well as "scarce resource". However, before metering could help to determine "fair" water tariffs, the industry ought to collect baseline data and deal with leaks. One participant admitted: "I'd quite happily meter everybody with intelligent meters and not charge people against the meter, it's so just we have the data." (Water Company).

\subsection{Theme 4: Tailored communication}

The discussions on the purpose and potential of metering concluded with recommendations for public engagement. Given the observation that there are (at least) two markets of consumers affected differently by metering (section 4.4.), future communications could reflect their needs, values and priorities:

Water Company: I am motivated to save water because of my personal commitment, that's not normally the case for people who can easily afford something. So I am interested in how you can engage with people on perhaps values-based basis.

Community Energy: I'd say that's exactly the same problem with energy, when we've done the studies where there are the wealthiest communities that are spending the most on their energy bills, but they're not caring about it.

Since Community Energy, Local Authority and Water Company participants agreed that metering alone would not reduce resource consumption, they suggested that public engagement should come in a "support package" form, together with tailored advice on smart appliances and appropriate building level schemes tackling draft and leaks at vulnerable households: 


\begin{abstract}
"You can make things visible to people, but if you just make more problems visible to them, you're adding stress so you're making their lives worse. If you offer support, like you both suggested [pointing at other discussants], it goes alongside that awareness raising. Smart metering needs to have that support package explaining how you can be a part of it and how you could benefit" (Community Energy)
\end{abstract}

Finally, six participants collectively critiqued the framings present in the current marketing materials and pointed out that the main priority is to create a compelling narrative, which refers to both individual and collective benefits (i.e. to the planet, society and service providers) of metering and smart technologies. "Starting with a person and then through the narrative coming to the community, I think that's when the marketing drive needs to be a bit personalised to the individual, but then stepping up...so the context and the country and then the planet". (Community Energy).

\title{
4.7. Critical reflections
}

The qualitative methodology, small sample size and geographic scale of the study suggest high contextuality of the results and point at the need for further research exploring different locations and organisations. Nevertheless, findings from the study provide valuable insights into the knowledge co-production approach. Detailed heuristics and critical reflections on discourse analysis, focus group recruitment and data analysis will facilitate reproducing results in future studies. Furthermore, validity and accuracy of the research were enhanced by combining two methods and sampling participants across a variety of sectors (Harris and Lyon, 2013).

By conducting cross-sectoral focus groups, the research informed the debate on metering, which usually takes place in sectoral siloes, separating practical and academic knowledge from each other. Hoolohan and Browne (2016) pointed out that the limited occurrences of participatory and deliberative methods deprived utility sectors of creativity essential for the introduction of the innovative DSM tools. In order to ensure inclusivity, further research on metering ought to tap into experiences of a wide variety of users and bring explicit attention into the notions of "smartness", "sustainability" and "fairness".

Despite their narrow geographical focus, the research outcomes are internationally relevant due to the ongoing rollout of smart technologies across the EU member states. Although the smart technologies advanced considerably over the past years, the EU member states are yet to understand the interplay between promotional strategies, sustainability/justice discourses and the future smart tariffs. Further research on the interactions between smart technologies and people could shed the light on the issue of the interplay between smart meters and user experiences.

\section{Conclusions}

By way of discourse analysis and focus groups, this paper unpacked assumptions and contradictions, which energy and water sectors have with regards to metering. The research found disparities in the customer-facing messages and perceived functionality of meters. First, the argument of metering as tools for "convenience" does not reveal much about the functionality of smart meters and it stands in opposition with the in-convenience experienced during the installation process. Furthermore, metering is advertised as a tool ensuring "control" over consumption, however, the utilities' professionals signal that the lay users tend to perceive "loss of control" due to potential privacy issues. Similarly, despite the industry promises of "fairness" and lower bills, metering would not address the issues of water and fuel 
poverty if deployed without the adequate public engagement, tariffs and support package. The research demonstrates that although practitioners across the public, private and community sectors highlight the imperative of "fair tariffs" and meeting "the basic level of need", the policy provision is yet to frame the above as a climate justice concern.

The analysis of research data concludes with the following recommendations for customer communication: a) a transparent and honest public engagement strategy which would refer to the full functionality of metering, the long-term ambitions of tariff re-design and benefits to the utilities sector; b) communication materials tailored to consumers' values and needs; c) metering deployment supported by a whole package of policy and communication, which includes advice on subsidised efficiency schemes at the building level. Only tailored and comprehensive policy design would reflect the reality of two distinct markets: early adopters and vulnerable households.

Finally, organising focus groups with both energy and water sectors professionals working for a variety of organisations created a novel space for engagement across the domains of WaterEnergy Nexus. Synthesis of secondary data reveals that although water and energy meters occupy different policy areas, they are both fundamentally concerned with the same issues of improved efficiency and fair provision. It can be therefore concluded that the nexus-type integrated decision-making has a chance to develop, provided that further collaborations and data sharing agreements will arise between utilities, academia and the government.

\section{Acknowledgements}

Many thanks to the research participants for their time, inputs and willingness to share data and disseminate the results.

We would like to thank the staff and volunteers of the Bristol Energy Network who facilitated the discussion of the draft results during internal meetings and a public-facing event.

Finally, we would like to thank our anonymous reviewers to their valuable suggestions on the manuscript.

\section{References}

1. Albrecht, T.R., Crootof, A. \& Scott, C.A. (2018) The Water-Energy-Food Nexus: A systematic review of methods for nexus assessment, Environmental Research Letters, vol. 13, no. 4, pp. 43002.

2. Bax. S (2011) Discourse and Genre: Using Language in Context. MacMillan: London

3. Beckel, C., Sadamori, L., Staake, T. \& Santini, S. (2014) Revealing household characteristics from smart meter data, Energy, vol. 78, pp. 397-410.

4. Bennet, O. (2013) Water bills and rateable values. House of Commons Briefing Paper [online] http://researchbriefings.parliament.uk/ResearchBriefing/Summary/SN06647\#fullrepo rt

5. Bertoldo, R., Poumadère, M. \& Rodrigues Jr, L.C. (2015) When meters start to talk: The public's encounter with smart meters in France, Energy Research \& Social Science, vol. 9, pp. 146-156.

6. Bradley, P., Fudge, S. \& Leach, M. (2016) Motivating energy conservation in organisations: smart metering and the emergence and diffusion of social norms, Technology Analysis \& Strategic Management, vol. 28, no. 4, pp. 435-461. 
7. Buchanan, K., Russo, R. \& Anderson, B. (2015) The question of energy reduction: The problem(s) with feedback. Energy Policy, vol. 77, pp. 89-89

8. Bristol City Council - BCC (2015) Deprivation in Bristol 2015. The mapping of deprivation within Bristol Local Authority Area [online] https://www.bristol.gov.uk/documents/20182/32951/Deprivation+in+Bristol+2015/429 b2004-eeff-44c5-8044-9e7dcd002faf

9. Bristol Energy (2016) Your smart meter and in-home display guide. [online] https://www.bristol-energy.co.uk/sites/default/files/Smart-Metering-Guide-WEBlow.pdf

10. Bristol Water (2016) Water meters explained. [online]. https://www.bristolwater.co.uk/your-home/water-meters/

11. Cairns, R. \& Krzywoszynska, A. (2016) Anatomy of a buzzword: The emergence of 'the water-energy-food nexus' in UK natural resource debates, Environmental Science and Policy, vol. 64, pp. 164-170.

12. Cheong, S., Choi, G. \& Lee, H. (2016) Barriers and Solutions to Smart Water Grid Development, Environmental Management, vol. 57, no. 3, pp. 509-515.

13. Citizens' Advice Bureau - CAB (2017) The Value of TOU Tariffs in Great Britain: Insights for Decision-makers. Final Report. [online] https://www.citizensadvice.org.uk/Global/CitizensAdvice/Energy/The\%20Value\%200 f\%20TOU\%20Tariffs\%20in\%20GB\%20-\%20Volume\%20I.pdf

14. Connecting Bristol (2016) Replicate Project - Overview [online] http://www.connectingbristol.org/replicate-project/

15. Department for Business Energy and Industrial Strategy - DBEIS (2015a) Subnational gas consumption data [online] https://www.gov.uk/government/collections/sub-national-gas-consumption-data

16. Department for Business Energy and Industrial Strategy -DBEIS (2017a) Fuel Poverty Statistics [online] https://www.gov.uk/government/collections/fuel-povertystatistics

17. Department for Business Energy and Industrial Strategy - DBEIS (2017b) Smart Meters: a guide [online] https://www.gov.uk/guidance/smart-meters-how-they-work

18. Departments for Communities and Local Governments - DCLG (2015) English indices of deprivation 2015. Official Statistics [online[ https://www.gov.uk/government/statistics/english-indices-of-deprivation-2015

19. Department for Energy and Climate Change- DECC- (2014) Percentage of households - fuel poor [online] http://profiles.bristol.gov.uk/IAS/dataviews/report?reportld=1206\&viewld=626\&geoR eportld=5203\&geold=26\&geoSubsetld $=$

20. Eid, C., Koliou, E., Valles, M., Reneses, J., Hakvoort, R., (2016) Time-based pricing and electricity demand response: Existing barriers and next steps, Utilities Policy, vol. 40, pp. 15-25.

21. European Commission (2012) Commission Recommendation of 9 March 2012 on preparations for the roll-out of smart metering systems (2012/148/EU) [online] https://ec.europa.eu/energy/en/topics/markets-and-consumers/smart-grids-andmeters

22. Fahradi, P. and Taheri, B. (2017) Smart Meter Tariff Pricing using Load Demand Response Model, Proceedings of the International Istanbul Smart Grids and Cities Conference and Fair [online] https://ieeexplore.ieee.org/document/7947618/

23. Harris, F. and Lyon, F. (2013) Transdisciplinary environmental research: Building trust across professional cultures, Environmental Science and Policy, vol. 31, pp. 109-119.

24. Helmbrecht, J., Pastor, J. \& Moya, C. (2017) Smart Solution to Improve Waterenergy Nexus for Water Supply Systems" Procedia Engineering, vol. 186, pp. 101109. 
25. Hielscher, S. \& Sovacool, B.K. (2018) Contested smart and low-carbon energy futures: Media discourses of smart meters in the United Kingdom, Journal of Cleaner Production, vol. 195, pp. 978-990.

26. Hoff, H., Iceland, C., Kuylenstierna, J., Dirk Willem Te Velde, Stockholms universitet, Stockholm Environment Institute \& Stockholm Resilience Centre (2012) Managing the Water-Land-Energy Nexus for Sustainable Development, UN Chronicle, vol. 49, no. $1 / 2$, pp. 34 .

27. Hoolohan, C. and Browne, A. (2016) On the practices of managing demand in the UK water industry management. DEMAND Centre Conference, Lancaster, 13-15 April 2016

28. Howarth, C. and Monasterolo, I. (2016) Understanding barriers to decision making in the UK energy-food-water nexus: The added value of interdisciplinary approaches. Environmental Science and Policy. 61 pp.53-60.

29. Jasanoff, S. (2010) A New Climate for Society, Theory, Culture \& Society, vol. 27, no. 2-3, pp. 233-253.

30. Knowle West Media Centre (2013) 3E Houses Project [online] http://kwmc.org.uk/projects/3ehouses/

31. Loftus, A. (2006) Reification and the Dictatorship of the Water Meter, Antipode, vol. 38, no. 5, pp. 1023-1045.

32. Loftus, A., March, H. \& Nash, F. (2016) Water infrastructure and the making of financial subjects in the south east of England, Water Alternatives, vol. 9, no. 2, pp. 319-335.

33. McKenna, E., Richardson, I. \& Thomson, M. (2012) Smart meter data: Balancing consumer privacy concerns with legitimate applications, Energy Policy, vol. 41, no. 1 , pp. 807-814.

34. Montginoul, M. \& Vestier, A. (2018) Smart metering: A water-saving solution? Consider communication strategies and user perceptions first. Evidence from a French case study" Environmental Modelling and Software, vol. 104, pp. 188-198.

35. Morgan, D.L. (1998) The Focus group guidebook. SAGE: London

36. Office for National Statistics - ONS (2017) Census Geography: An overview of the various geographies used in the production of statistics collected via the UK census. [online] https://www.ons.gov.uk/methodology/geography/ukgeographies/censusgeography

37. Ofwat (2013) Water meters -your questions answered. Information for household customers [online] https://www.ofwat.gov.uk/wpcontent/uploads/2015/11/prs lft 101117meters.pdf

38. Ofwat (2017) Unmetered customers [online] https://www.ofwat.gov.uk/households/your-water-bill/unmetered/

39. Priestley, S. (2016) Water meters: the rights of customers and water companies. House of Commons Briefing Paper [online] https://researchbriefings.parliament.uk/ResearchBriefing/Summary/CBP-7342

40. Stewart, R.A., Nguyen, K., Beal, C., Zhang, H., Sahin, O., Bertone, E., Vieira, A.S., Castelletti, A., Cominola, A., Giuliani, M., Giurco, D., Blumenstein, M., Turner, A., Liu, A., Kenway, S., Savić, D.A., Makropoulos, C. \& Kossieris, P. (2018) Integrated intelligent water-energy metering systems and informatics: Visioning a digital multiutility service provider, Environmental Modelling and Software, vol. 105, pp. 94-117.

41. Seyranian, V., Sinatra, G.M. \& Polikoff, M.S. (2015) Comparing communication strategies for reducing residential water consumption, Journal of Environmental Psychology, vol. 41, pp. 81-90

42. Shove, E. (2010) Beyond the ABC: Climate Change Policy and Theories of Social Change, Environment and Planning A, vol. 42, no. 6, pp. 1273-1285. 
43. Sibly, H. \& Tooth, R. (2014) The consequences of using increasing block tariffs to price urban water, Australian Journal of Agricultural and Resource Economics, vol. 58, no. 2, pp. 223-243.

44. Smart Energy GB (2017) About Smart Energy GB https://www.smartenergygb.org/en/about-us/about-smart-energy-gb

45. Sovacool, B.K.; Heffron, R.J.; McCauley, D.; Goldthau, A. (2016) Energy decisions reframed as justice and ethical concerns. Nature Energy,

46. Sovacool, B.K., Kivimaa, P., Hielscher, S. \& Jenkins, K. (2017) Vulnerability and resistance in the United Kingdom's smart meter transition, Energy Policy, vol. 109, pp. 767-781.

47. Spence, A., Demski, C., Butler, C., Parkhill, K. \& Pidgeon, N. (2015) Public perceptions of demand-side management and a smarter energy future, Nature Climate Change, vol. 5, no. 6, pp. 550-554.

48. Torriti, J. (2017) Understanding the timing of energy demand through time use data: Time of the day dependence of social practices. Energy Research \& Social Science 25, pp. 37-47

49. Zhang, T., Siebers, P. \& Aickelin, U. (2016) Simulating user learning in authoritative technology adoption: An agent based model for council-led smart meter deployment planning in the UK, Technological Forecasting \& Social Change, vol. 106, pp. 74-84 